\title{
In vitro effects of Bifidobacterium lactis- based synbiotics on human faecal bacteria
}

\section{Article}

\section{Accepted Version}

Creative Commons: Attribution-Noncommercial-No Derivative Works 4.0

Henrique-Bana, F. C., Wang, X., Costa, G. N., Spinosa, W. A., Miglioranza, L. H. S., Scorletti, E., Calder, P. C., Byrne, C. D. and Gibson, G. (2020) In vitro effects of Bifidobacterium lactisbased synbiotics on human faecal bacteria. Food Research International, 128. 108776. ISSN 0963-9969 doi: https://doi.org/10.1016/j.foodres.2019.108776 Available at https://centaur.reading.ac.uk/89759/

It is advisable to refer to the publisher's version if you intend to cite from the work. See Guidance on citing.

To link to this article DOI: http://dx.doi.org/10.1016/j.foodres.2019.108776

Publisher: Elsevier

All outputs in CentAUR are protected by Intellectual Property Rights law, including copyright law. Copyright and IPR is retained by the creators or other copyright holders. Terms and conditions for use of this material are defined in the End User Agreement.

\section{www.reading.ac.uk/centaur}

\section{CentAUR}


Central Archive at the University of Reading

Reading's research outputs online 
Henrique-Bana, F. C., Wang, X., Costa, G. N., Spinosa, W. A., Miglioranza, L. H.

\title{
S., Scorletti, E., Calder, P. C., Byrne, C. D. and Gibson, G. In vitro effects of
}

Bifidobacterium lactis-based synbiotics on human faecal bacteria.

\begin{abstract}
Synbiotics are dietary means of modulating gut microbiota composition and activities. This study aimed to investigate the in vitro potential fermentation properties of two synbiotic mixtures on human faecal bacteria from healthy persons. The selected synbiotics (fructo-oligosaccharide (FOS) (1\%) combined with Bifidobacterium lactis BB12 or Bifidobacterium lactis HN019 $\left(10^{6}\right.$ colony-forming units (CFU)/mL)) were added to 48-h pH-controlled anaerobic batch cultures reflective of the distal region of the human large intestine. Maltodextrin, FOS and the probiotic components were also tested alone. Effects upon major groups of the microbiota were monitored during a time course by fluorescence in situ hybridisation (FISH). Short-chain fatty acids (SCFA) were measured by gas chromatography (GC).

Quantitative analysis of bacterial populations revealed that there was a significant increase $(\mathrm{P}<0.05)$ in bifidobacterial numbers in vessels with FOS and the synbiotic mixtures compared to the negative control. Levels of Clostridium coccoidesEubacterium rectale group significantly increased $(\mathrm{P}<0.05)$ at 8 and $24 \mathrm{~h}$ of fermentation with maltodextrin, whereas Atopobium cluster increased after $8 \mathrm{~h}$ of FOS fermentation.

Additionally, vessels containing carbohydrates promoted shifts in the production of SCFA. Fermentation of FOS and synbiotic mixtures at all time points resulted in a greater production of acetate and butyrate compared to a negative control, whereas the concentrations of iso-valerate were lower in these three treatments. Lactate concentrations were higher only after $8 \mathrm{~h}$ of fermentation with maltodextrin, FOS and the synbiotic mixtures.
\end{abstract}

Conclusion: Probiotics alone had no significant effect upon relevant microbial populations and SCFA. The effects of synbiotic mixtures on human faecal bacteria were similar to FOS as a prebiotic. 


\section{Objective}

To study the in vitro fermentation properties of two synbiotic mixtures (FOS + Bifidobacterium lactis BB12 and FOS + Bifidobacterium lactis HN019) on human faecal bacteria of healthy humans.

1) Investigate the growth of total bacteria and 11 functionally significant faecal microbial groups in a $\mathrm{pH}$-controlled, stirred, batch-culture fermentation system reflective of the environmental conditions of the distal region of the human large intestine.

2) Analyse the production of selected short-chain fatty acid (SCFA).

\section{Materials and methods}

\section{Methods}

Substrates

Fructo-oligosaccharide with a degree of polymerisation $<10$ and maltodextrin were supplied by University Hospital Southampton NHS Foundation Trust. Freezedried Bifidobacterium animalis subsp. lactis HN019 (DuPont-Danisco, Madison, USA) and Bifidobacterium animalis subsp. lactis BB12 (Chr. Hansen, Hørsholm, Denmark) were stored at $-80{ }^{\circ} \mathrm{C}$. Plates of de Man-Rogosa-Sharpe (MRS) agar (Oxoid Ltd, Basingstoke, Hampshire, UK) were inoculated with the bifidobacterial strains and incubated at $37^{\circ} \mathrm{C}$ in an anaerobic chamber $\left(10 \% \mathrm{CO}_{2}, 10 \% \mathrm{H}_{2}\right.$ and $80 \% \mathrm{~N}_{2}$, Don Whitley Scientific LTD, Shipley, West Yorkshire, UK). After incubation, bottles containing $9 \mathrm{~mL}$ of MRS broth were then inoculated with one colony from each plate. The cultured broths of probiotics were incubated for $24 \mathrm{~h}$ under the same conditions as mentioned above.

\section{Faecal sample preparation}

Faecal samples were collected from three separate individuals ( 2 women and 1 man aged between 25 and 35y) who were in good health, were not taking probiotic or prebiotic supplements and had not had antibiotics for at least 3 months before the study. Samples were collected, on site, on the day of the experiment and placed in an 
anaerobic jar (AnaeroJar ${ }^{\mathrm{TM}}$ 2.5L, Oxoid Ltd), including a gas-generating kit (AnaeroGen ${ }^{\mathrm{TM}}$, Oxoid). Then, samples were weighed, diluted, 1:10 (w/v), with anaerobic sterile PBS $(0.1 \mathrm{~mol} / \mathrm{L}$ phosphate buffer solution, $\mathrm{pH} 7.4)$ and homogenised (Stomacher 400; Seward) for $2 \mathrm{~min}$ at 240 paddle/min. Resulting faecal slurries from each individual were used to inoculate the batch culture fermentation systems.

\section{In vitro batch culture fermentation}

Sterile stirred batch culture fermentation vessels (300 $\mathrm{mL}$ working volume) were prepared and aseptically filled with $135 \mathrm{~mL}$ of sterile basal nutrient medium (peptone water $(2 \mathrm{~g} / \mathrm{l})$, yeast extract $(2 \mathrm{~g} / \mathrm{l}), \mathrm{NaCl}(0.1 \mathrm{~g} / \mathrm{l}), \mathrm{K}_{2} \mathrm{HPO}_{4}(0.04 \mathrm{~g} / \mathrm{l}), \mathrm{NaCO}_{3}(2 \mathrm{~g} / \mathrm{l})$, $\mathrm{MgSO}_{4} .7 \mathrm{H}_{2} \mathrm{O}(0.01 \mathrm{~g} / \mathrm{l}), \mathrm{CaCl}_{2} .6 \mathrm{H}_{2} \mathrm{O}(0.01 \mathrm{~g} / \mathrm{l})$, Tween $80(2 \mathrm{ml} / \mathrm{l})$, haemin $(50 \mathrm{mg} / \mathrm{l})$, vitamin K1 (10 ll/l), L-cysteine $(0.5 \mathrm{~g} / \mathrm{l})$, bile salts $(0.5 \mathrm{~g} / \mathrm{l})$, resazurin $(1 \mathrm{mg} / \mathrm{l})$ and distilled water). Once in the fermentation vessels, sterile medium was maintained under anaerobic conditions by sparging the vessels with $\mathrm{O}_{2}$-free $\mathrm{N}_{2}$ overnight. Temperature was held at $37{ }^{\circ} \mathrm{C}$ using a circulating water bath and $\mathrm{pH}$ values controlled between 6.7 and 6.9 using an automated pH controller (Fermac 260; Electrolab, Tewkesbury, UK) which added acid or alkali as required $(0.5 \mathrm{M} \mathrm{HCl}$ and $0.5 \mathrm{M} \mathrm{NaOH})$. Culture $\mathrm{pH}$ and temperature mimicked the conditions of the distal region of the human large intestine.

Seven gently stirred $\mathrm{pH}$-controlled batch fermenters were run in parallel. Two vessels were inoculated with the carbohydrates FOS and maltodextrin (1\% w/v) and another set of two vessels were inoculated with $1 \mathrm{~mL}$ of a suspension of B. lactis HN019 and B. lactis BB12 $\left(10^{6} \mathrm{CFU} \mathrm{mL}^{-1}\right)$, respectively. The two synbiotic vessels were inoculated with FOS combined with B. lactis HN019 and B. lactis BB12 at the same concentrations as above. Finally, a control with neither probiotics nor carbohydrates added (negative control) was also included.

The experiment was performed in triplicate, using one faecal sample given by a different donor for each run of seven batch fermenters. Probiotics and carbohydrates were added to each vessel just before the addition of $15 \mathrm{~mL}(1: 10, \mathrm{w} / \mathrm{v})$ of fresh faecal slurry, prepared as described above. Batch cultures were conducted for $48 \mathrm{~h}$, and $4 \mathrm{~mL}$ samples obtained from each vessel at $0,8,24$ and $48 \mathrm{~h}$ for analysis of bacterial populations by fluorescent I situ hybridization (FISH) and for SCFA analyses using gas chromatography (GC). 
Bacterial composition in the batch culture models was analysed by FISH with flow cytometry (FISH-FCM). Seven hundred and fifty microlitres of samples were centrifuged at $1136 \times \mathrm{g}$ for $5 \mathrm{~min}$. Pellets were resuspended in $375 \mu \mathrm{L}$ of filtered PBS and fixed in $1125 \mu \mathrm{L}$ of $4 \%(\mathrm{v} / \mathrm{v})$ paraformaldehyde. After $4 \mathrm{~h}$ of incubation at $4^{\circ} \mathrm{C}$, samples were washed twice using $1 \mathrm{~mL}$ of PBS, resuspended in $600 \mu \mathrm{L}$ PBS-ethanol $(1: 1, \mathrm{v} / \mathrm{v})$ and stored at $-20^{\circ} \mathrm{C}$. Permeabilisation steps were performed using $30 \mu \mathrm{L}$ of the fixed samples added to $500 \mu \mathrm{L}$ PBS and centrifuged at $1136 \times \mathrm{g}$ for $3 \mathrm{~min}$. Pellets were resuspended using $100 \mu \mathrm{L}$ of filtered TE-FISH (Tris/HCl $1 \mathrm{M} \mathrm{pH} \mathrm{8,} \mathrm{EDTA} 0.5 \mathrm{M}$ $\mathrm{pH} 8$, distilled H2O, $0.22 \mu \mathrm{m}$ PVDF membrane) containing lysozyme ( $1 \mathrm{mg} / \mathrm{mL}$ of 50 $000 \mathrm{U} / \mathrm{mg}$ protein) and incubated for $10 \mathrm{~min}$ at room temperature. Solutions containing the samples were then vortexed and centrifuged at $1136 \times \mathrm{g}$ for $3 \mathrm{~min}$. Pellets were washed with $500 \mu \mathrm{L}$ PBS and centrifuged $(1136 \times \mathrm{g}, 3 \mathrm{~min})$. Hybridisations were performed by resuspending the pellets in $150 \mu \mathrm{L}$ of hybridisation buffer $(5 \mathrm{M} \mathrm{NaCl}, 1$ $\mathrm{M}$ Tris/ $\mathrm{HCl} \mathrm{pH} 8,30 \%$ formamide, $\mathrm{ddH} 2 \mathrm{O}, 10 \% \mathrm{SDS}$ ), vortexed and centrifuged (1136 $\times \mathrm{g}, 3 \mathrm{~min}$ ). Pellets were then resuspended in $1 \mathrm{~mL}$ of hybridisation buffer and $50 \mu \mathrm{L}$ aliquoted into Eppendorf tubes.

Probes used (Sigma Aldrich Ltd, Poole, Dorset, UK) are shown in Table 1. Four microliters of each probe and $4 \mu \mathrm{L}$ of Eub338 I-II-III were added to the working solution and incubated overnight at $35^{\circ} \mathrm{C}$ in a heating block. After $12 \mathrm{~h}$ of incubation, an aliquot of $150 \mu \mathrm{L}$ hybridisation buffer was added to the working solution, vortexed and centrifuged $(1136 \times \mathrm{g}, 3 \mathrm{~min})$. One hundred and fifty microlitres of supernatant was removed from each sample and the remaining volume centrifuged $(1136 \times \mathrm{g}, 3 \mathrm{~min})$. The pellets were washed with $200 \mu \mathrm{L}$ of washing buffer $(5 \mathrm{M} \mathrm{NaCl}, 1 \mathrm{M}$ Tris/ $\mathrm{HCl} \mathrm{pH} 8$, $0.5 \mathrm{M}$ EDTA $\mathrm{pH} 8, \mathrm{ddH} 2 \mathrm{O}, 10 \% \mathrm{SDS}$ ), homogenised by vortexing and incubated for 20 $\min$ at $37^{\circ} \mathrm{C}$ in a heating block. Afterwards, samples were centrifuged $(1136 \times \mathrm{g}, 3 \mathrm{~min})$ and supernatants removed. Negative control samples (no probes added) were screened by FCM to detect background before the probe samples were resuspended in an appropriate amount of PBS. Samples were stored at $4{ }^{\circ} \mathrm{C}$ until determination. Numbers of specific and total bacteria were assessed taking into account dilution factor, calculated from different volumes used in samples preparation steps, and events $/ \mu \mathrm{L}$ obtained from NON EUB338 and EUB338 I-II-III probes analysed by FCM. 
Aliquots of $1 \mathrm{~mL}$ of samples supernatant were transferred into glass tubes, followed by the addition of $50 \mu \mathrm{L}$ of internal standard (100 mM; 2-ethylbutyric acid), $500 \mu \mathrm{L}$ of concentrated hydrochloric acid $(\mathrm{HCl})$ and $3 \mathrm{~mL}$ of diethyl ether (Sigma Aldrich Ltd., Poole, Dorset, UK). Samples were then vortexed for 1 min before centrifugation at 3,000 x g for $10 \mathrm{~min}$. The top ether layer was transferred from each tube into clean glass tubes. A second extraction step was then completed using a further $1 \mathrm{~mL}$ of diethyl ether. The diethyl layer was again collected and pooled with the layer from the first extraction. Aliquots of $400 \mu \mathrm{L}$ of this pooled extract were transferred into glass vials, alongside $50 \mu \mathrm{L}$ of $\mathrm{N}$-methyl-N-tbutyldimethylsilyltrifluoroacetamide (Cheshire Sciences, Chester, UK). Samples were then incubated at $80^{\circ} \mathrm{C}$ in a water bath for $20 \mathrm{~min}$ and left at room temperature for $72 \mathrm{~h}$ to allow for the complete derivatisation of lactic acid.

The derivatised samples were run on a 5890 Series II Gas Chromatograph (HP, Crawley, West Sussex, UK) with flame ionisation detector, using an Rtx-1 $10 \mathrm{~m} \times 0.18 \mathrm{~mm}$ column coated with a $0.20 \mu \mathrm{m}$ coating (Crossbond $100 \%$ dimethyl polysiloxane; Restek, Buckinghamshire, UK). Injector and detector temperature were set at $275^{\circ} \mathrm{C}$ and the column temperature programmed from $63^{\circ} \mathrm{C}$ for 3 min to $190^{\circ} \mathrm{C}$ at $10^{\circ} \mathrm{C} / \mathrm{min}-1$ and held at $190{ }^{\circ} \mathrm{C}$ for $3 \mathrm{~min}$. Helium was used as the carrier gas (flow rate $1.2 \mathrm{~mL} / \mathrm{min}$; head pressure $90 \mathrm{MPa})$. External standards contained $(\mathrm{mM})$ : sodium formate, 10; acetic acid, 30; propionic acid, 20; iso-butyric acid, 5; n-butyric acid, 20; isovaleric acid, 5; n-valeric acid, 5; sodium lactate, 10; sodium succinate, 20. Chemstation B.03.01 (Agilent Technologies, Cheshire, UK) was used for calibration and calculation of the internal response factor for quantification of peak areas within samples.

\section{Statistical analysis}

One-way ANOVA tests were used to compare treatments data for bacterial counts and SCFA concentrations. The data of each treatment were compared over the same time of fermentation. Mean values were then analysed using the post hoc analysis Tukey test at $\mathrm{P} \leq 0.05$ by Statistica software version 10.0 (Statsoft South America).

Table 1. Oligonucleotide probes used in this study for FISH-FCM analysis of bacterial populations. + : These probes are used together in equimolar concentration of $50 \mathrm{ng} / \mu \mathrm{L}$.

\begin{tabular}{lll}
\hline Probe name & Sequence (5' TO 3') & Target group
\end{tabular}




\begin{tabular}{|c|c|c|}
\hline Non Eub & ACTCCTACGGGAGGCAGC & \\
\hline Eub338 I + & GCT GCC TCC CGT AGG AGT & Most bacteria \\
\hline Eub338 II + & GCA GCC ACC CGT AGG TGT & Planctomycetales \\
\hline Eub338 III + & GCT GCC ACC CGT AGG TGT & Verrucomicrobiales \\
\hline Bif164 & CAT CCG GCA TTA CCA CCC & $\begin{array}{l}\text { Most Bifidobacterium spp. and } \\
\text { Parascardovia } \\
\text { denticolens }\end{array}$ \\
\hline Lab158 & GGTATTAGCAYCTGTTTCCA & $\begin{array}{l}\text { Most Lactobacillus, Leuconostoc and } \\
\text { Weissella spp.; Lactococcus lactis; all } \\
\text { Vagococcus, Enterococcus, } \\
\text { Melisococcus, Tetragenococcus, } \\
\text { Catellicoccus, Pediococcus and } \\
\text { Paralactobacillus spp, }\end{array}$ \\
\hline Bac303 & CCA ATG TGG GGG ACC TT & $\begin{array}{l}\text { Most Bacteroidaceae and } \\
\text { Prevotellaceae, some } \\
\text { Porphyromonadaceae }\end{array}$ \\
\hline Erec482 & GCT TCT TAG TCA RGT ACCG & $\begin{array}{l}\text { Most of the Clostridium coccoides- } \\
\text { Eubacterium rectale group } \\
\text { (Clostridium clusters XIVa and XIVb) }\end{array}$ \\
\hline Rrec584 & TCA GAC TTG CCG YAC CGC & Roseburia subcluster \\
\hline Ato291 & GGT CGG TCT CTC AAC CC & $\begin{array}{l}\text { Atopobium, Colinsella, Olsenella and } \\
\text { Eggerthella spp.; Cryptobacterium } \\
\text { curtum; Mycoplasma equigenitalium } \\
\text { and Mycoplasma elephantis }\end{array}$ \\
\hline Prop853 & ATT GCG TTA ACT CCG GCAC & Clostridial cluster IX \\
\hline Fprau655 & CGCCTACCTCTGCACTAC & $\begin{array}{l}\text { Faecalibacterium prausnitzii and } \\
\text { related sequences }\end{array}$ \\
\hline DSV687 & TAC GGA TTT CAC TCC T & $\begin{array}{l}\text { Most Desulfovibrionales (excluding } \\
\text { Lawsonia) and many } \\
\text { Desulfuromonales }\end{array}$ \\
\hline Chis 150 & TTATGCGGTATTAATCTYCCTTT & $\begin{array}{l}\text { Most of the Clostridium histolyticum } \\
\text { group (Clostridium clusters I and II) }\end{array}$ \\
\hline CFB286 & GTAGGGGTTCTGAGAGGA & Cytophaga-Flexibacter-Bacteroides \\
\hline
\end{tabular}

Results

Bacterial Enumeration by FISH

In order to determine bacterial population changes, 16S-rRNA fluorescent in situ hybridisation probes were used to follow the changes in population of total bacteria and 11 functionally significant faecal microbial groups (at $0,8,24$ and $48 \mathrm{~h}$ of incubation).

Trends to increases in maltodextrin, FOS and both synbiotic vessels were observed for total bacterial levels (detected by Eub I-II-III probe), however no significant changes were found, the highest number was detected in the fermentation with BB12 + FOS at $8 \mathrm{~h}\left(\log _{10} 8.34 \pm 0.18\right.$ bacteria $\left.\mathrm{mL}^{-1}\right)$.

A significant increase in Bifidobacterium spp. numbers (detected by Bif164 probe) was observed for FOS and synbiotic mixtures compared to probiotic vessels and the negative control $(\mathrm{P}<0.05)$. Regarding Lactobacillus-Enterococcus group (detected by 
Lab158 probe), no significant changes were observed at all time points, however, highest numbers were detected in the fermentation with FOS at $24 \mathrm{~h}\left(\log _{10} 6.24 \pm 0.45\right.$ bacteria $\left.\mathrm{mL}^{-1}\right)$.

Levels of Clostridium coccoides-Eubacterium rectale group (detected by Erec482 probe) significantly increased $(\mathrm{P}<0.05)$ at 8 and $24 \mathrm{~h}$ of fermentation with maltodextrin $\left(\log _{10} 6.61 \pm 0.23\right.$ to $7.63 \pm 0.53$ bacteria $\left.\mathrm{mL}^{-1}\right)$. An increase in Atopobium cluster (detected by Ato291 probe) was observed with FOS fermentation at $8 \mathrm{~h}\left(\log _{10}\right.$ $5.12 \pm 0.59$ to $7.02 \pm 0.54$ bacteria $\mathrm{mL}^{-1}$ ). Because of high variations between the volunteers at 8 and $24 \mathrm{~h}$, the increase in the Atopobium cluster was not significant for maltodextrin and synbiotic mixtures compared with $0 \mathrm{~h}$.

No significant differences were found for the other bacterial groups analysed, including Bacteroides spp.-Prevotella group (Bac303 probe), Roseburia genus (Rrec584 probe), Clostridial cluster IX populations (Prop853 probe), F. prausnitzii group (Fprau655 probe), Desulfovibrio genus (DSV687 probe), Clostridium histolyticum group (Chis150 probe) and Cytophaga-Flexibacter-Bacteroides (CFB286 probe). 

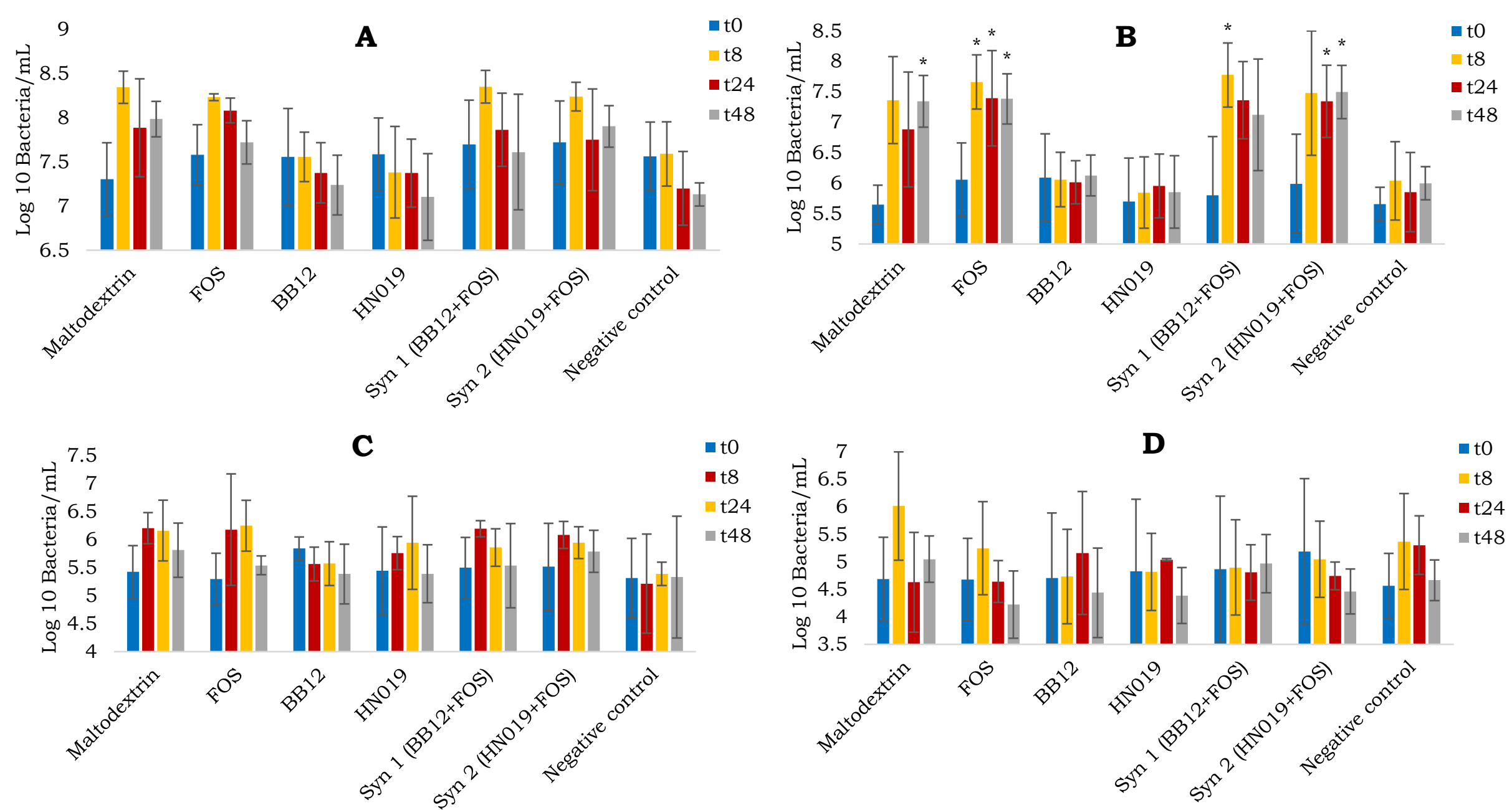

Figure 1. Total bacterial (A), Bif164 (B), Lab158 (C) and Bac303 (D) changes over time as $\log _{10} \mathrm{CFU} / \mathrm{mL}$ in the single stage batch culture as analysed by FISH. Values are mean values at four time points from three healthy faecal donor's \pm standard deviation. * Mean values were significantly different from $0 \mathrm{~h}$ fermentation ( $<<0.05$ ). 

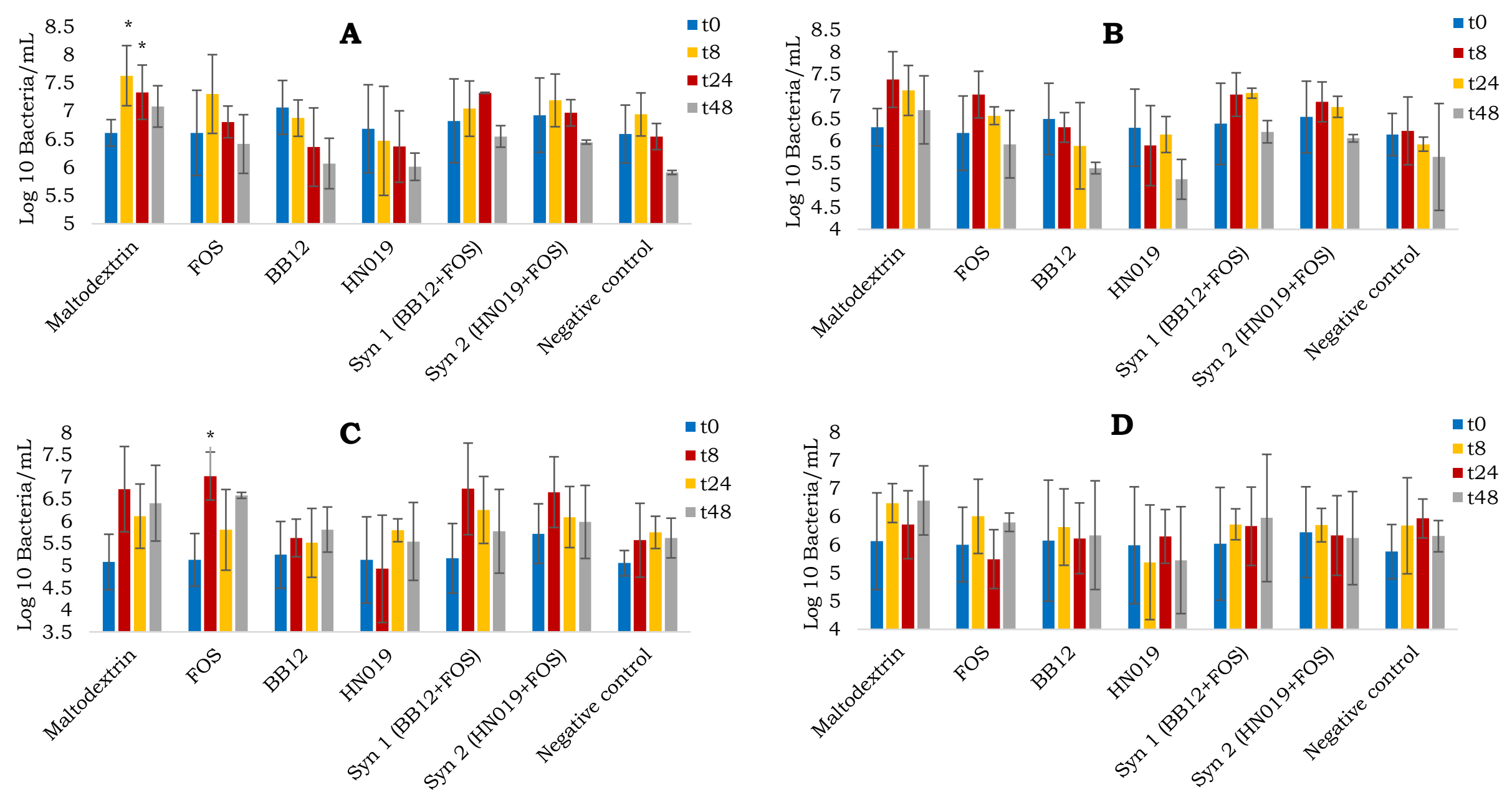

Figure 2. Erec482 (A), Rrec584 (B), Ato291 (C) and Prop853 (D) changes over time as $\log _{10} \mathrm{CFU} / \mathrm{mL}$ in the single stage batch culture as analysed by FISH. Values are mean values at four time points from three healthy faecal donor's \pm standard deviation. * Mean values were significantly different from $0 \mathrm{~h}$ fermentation ( $<<0.05$ ). 

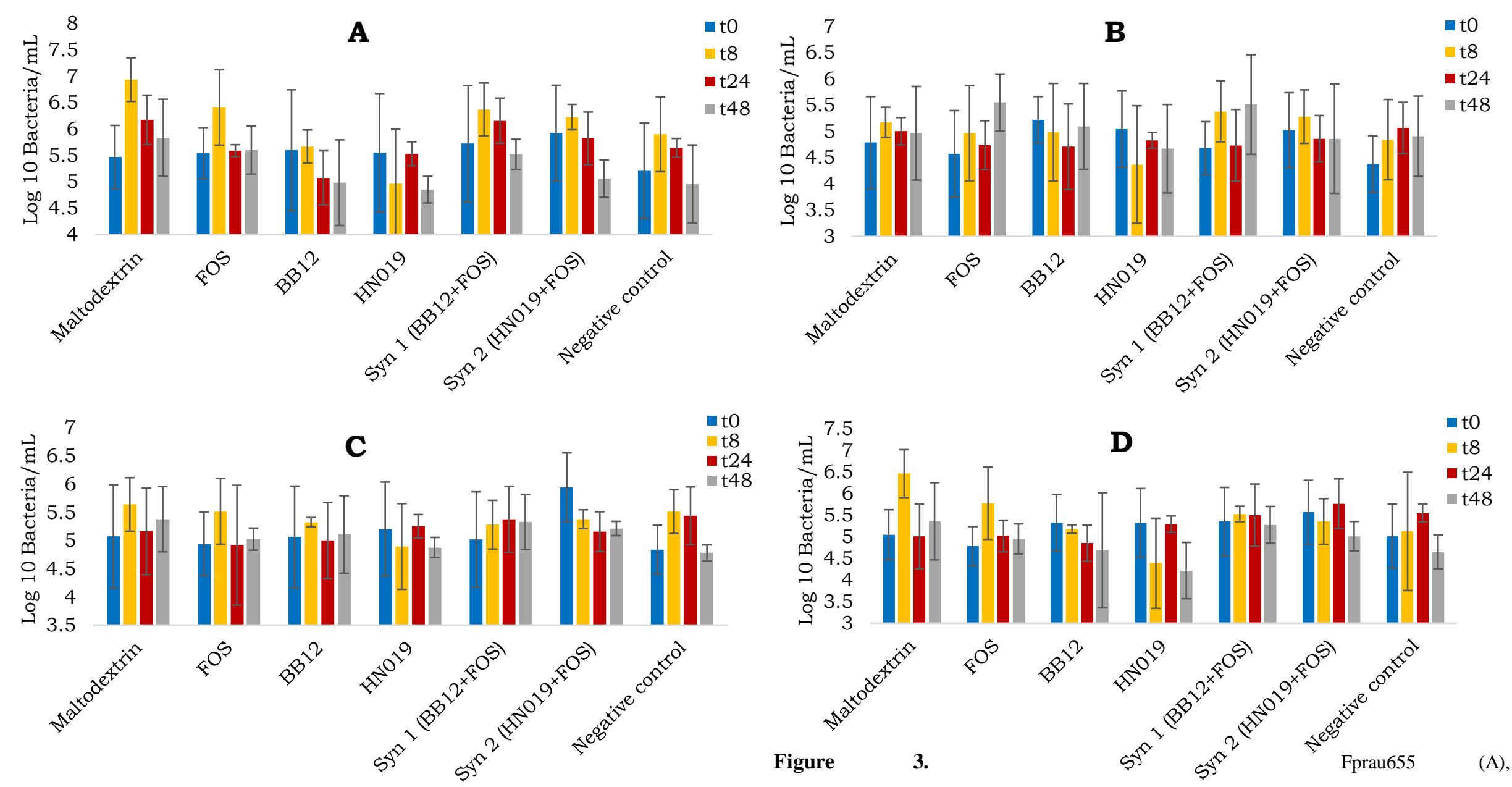

DSV687 (B), Chis150 (C) and CFB286 (D) changes over time as $\log _{10}$ CFU/mL in the single stage batch culture as analysed by FISH. Values are mean values at four time points from three healthy faecal donor's \pm standard deviation. * Mean values were significantly different from $0 \mathrm{~h}$ fermentation $(\mathrm{p}<0.05)$. 
SCFAs such as acetic, propionic and butyric acid can affect health positively. Folowing administration of all treatments, acetate was the main end product of microbial fermentation. Acetate concentrations increased $(\mathrm{P}<0.05)$ on maltodextrin, FOS and synbiotic vessels compared to the negative control and the probiotics, however there were no significant differences.

Production of butyrate was also higher $(\mathrm{P}<0.05)$ in the vessels with maltodextrin, FOS and synbiotic addition compared to the negative control. Propionate increased in all vessels compared with $0 \mathrm{~h}$, however because of high variations between the volunteers at 24 and $48 \mathrm{~h}$, the increase of this SCFA with maltodextrin, FOS and synbiotic fermentation was not significant compared to the negative control. Lactate concentrations were higher only after $8 \mathrm{~h}$ of fermentation in the vessels containing carbohydrates - as it is an electron sink product.

On the other hand, isovalerate, a branched-chain fatty acids (BCFA) from amino acid metabolism was higher in the probiotic vessels and the negative control after 24 and $48 \mathrm{~h}$ of fermentation. The presence of maltodextrin and FOS may have inhibited production of this BCFA. No differences were found in valerate or isobutyrate. 

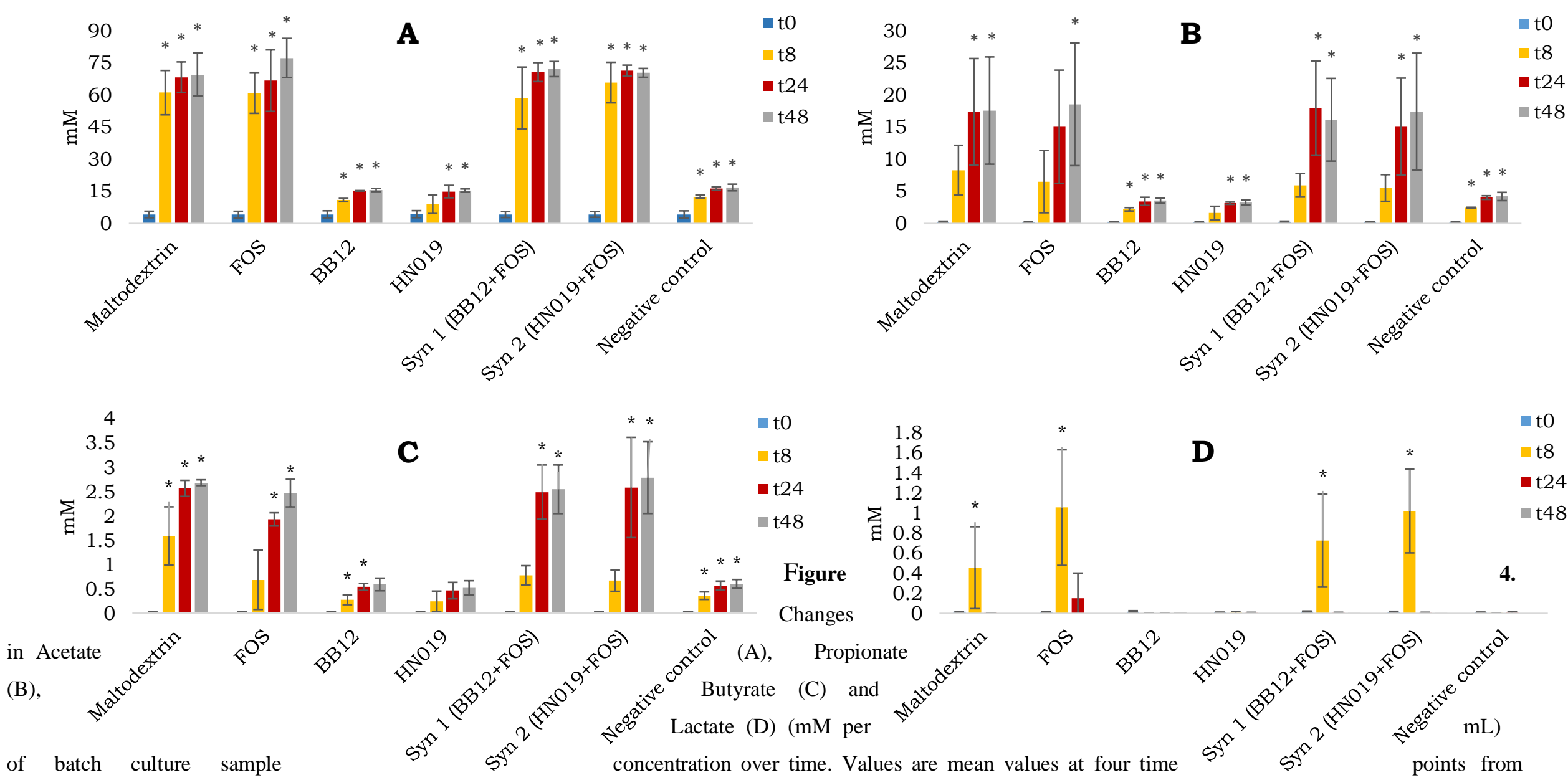

three healthy faecal donor's \pm standard deviation. * Mean values were significantly different from $0 \mathrm{~h}$ fermentation $(\mathrm{p}<0.05)$. 

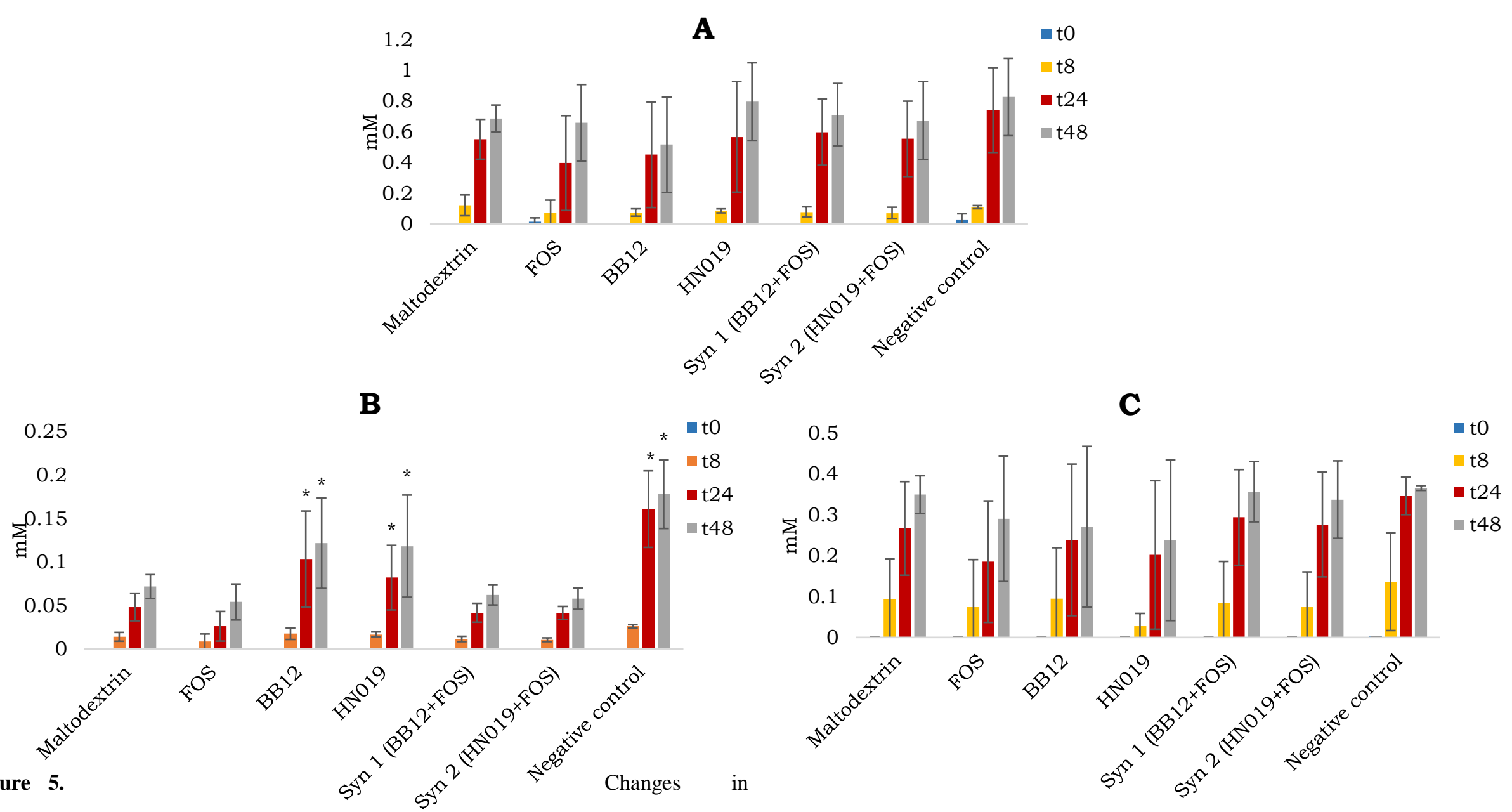

Isobutyrate (A), Isovalerate (B) and Valerate

(C) and Lactate (D) (mM per

$\mathrm{mL}$ ) of batch culture sample concentration over time. Values are mean values at four time points from three healthy faecal donor's \pm standard deviation. * Mean values were significantly different from $0 \mathrm{~h}$ fermentation $(\mathrm{p}<0.05)$. 